\title{
The doctor-patient relationship and psychiatric out-patients
}

\author{
SAMI B. Timimi, 16 Northland Street, Camberwell, London SE5 9PL
}

A trainee in psychiatry soon realises that one of the great differences between working in psychiatry and in other specialities is the presence of different working models, each with its own boundaries, which are often kept quite separate in clinical practice (see, for example, Straus et al, 1964). This naturally presents the newcomer with many dilemmas. In this paper I want to explore my own experiences in using psychodynamic approaches within the setting of a routine (medical model) psychiatric out-patient clinic.

I have used case material to illustrate a number of situations where psychodynamic understanding proved useful. The material highlights important issues, including transference dependency, the importance of making human contact with the patient, the possiblity of the ill patient being part of an "ill" family system, and the importance of having an awareness of one's own counter-transference feelings.

\section{Case material}

I was first sensitised to the importance of understanding the doctor/patient relationship in this setting after a powerful transference neurosis developed in the following patient's relationship with me.

Case 1: Mrs C. is a 39-year-old woman with two children. Her husband left her two months before she came to the clinic. She complained of depression and feelings of worthlessness. The separation had happened out of the blue. Her husband had rung her from work one day to say that he no longer loved her. Within three weeks, he had left the marital home and had confessed to restarting an affair with an "old flame". Mrs C. started attending 'Relate' for counselling, but this did not appear to help her. She was then seen for two months by my predecessor and was appropriately started on anti-depressant medication. Initially, I continued a similar approach, seeing her every 3-4 weeks.

After three months, she began to ask if she was "wasting my time". This appeared to be testing my commitment to her, as she was also complaining of feeling worse. I decided to see her once a fortnight for 30 minutes. During the following four months (until I had finished the post) her dependence on me grew. "I suppose I feel safe here", she would say. She reported becoming obsessed with images and fantasies of a relationship with me. She began acting out by staying behind in the waiting room after clinic, crying and telling the secretary she could not go home. She became angry and accused me of not caring when I left the clinic after seeing her again only briefly.

As the time for separation approached, she was mobilising increasing concern and guilt in me. "Should I increase her medication?" "Maybe she really can't cope - maybe she needs hospitalisation". It eventually became clear that these would have been the feelings she would have wished to arouse in her husband had she had more time prior to their separation. She only finally acknowledged the connection between myself and her husband in the final appointment. She checked the date I would be leaving the hospital, then said that she would not be able to let go of her obsession with me (e.g. looking for me in passing cars) until that date passed. "It'll be like two losses then, yours and my husband's". After that she thought she might be able to accept that her husband was not returning. Mrs C's dependancy demonstrates the intensity of her needs, and also gives insight into the possible dependent pattern of interaction that may have contributed to the husband's departure.

Repeated patterns often give important clues to the nature of one's relationship with patients.

Case 2: $\mathrm{Mr} \mathrm{M}$. is a single man in his early $30 \mathrm{~s}$, lives alone and is unemployed. He had been attending the psychiatric clinic for many years, had a diagnosis of chronic schizophrenia, had a history of a previous hospitalisation and was on a large assortment of psychotropic medication. After months of seeing him regularly, it became noticeable that the pattern of the appointments was being repeated. After an initial cordial exchange, we would get down to business. He would go through any variations in his symptoms since last seen and then we would have an active exchange as to how the medication could be varied to deal with this. He had considerable knowledge of psychotropic medication and was able to discuss the subject intelligently. On being confronted with this observation, he told me that he felt he needed to "play this game" with doctors. He complained that whenever he communicated some of 
his ideas and beliefs (delusional in nature) he was told that these were symptoms of schizophrenia and no more interest was taken in that side of himself. $\mathrm{He}$ learnt that doctors were interested in medication and so he became an "expert" in the subject. He felt frustrated and, with a sense of sadness, told me that coming to the clinic was important to him; he wanted to feel that someone listened to him and showed care and concern. The nature of my relationship with him changed after that. I wondered whether what happened was what members of the Balint society describe as a "flash" (Balint \& Norell, 1973) where a brief, intense, close contact can change the nature of the relationship with the patient. I also found that relationship issues do not only have to occur in the patient you are most directly concerned with.

Case 3: Mrs Mc was in her early 50s with a diagnosis of manic depression and a history of previous hospitalisation. I had to actively involve her husband and youngest daughter to discuss and work through her difficulty in allowing her youngest daughter, who was wanting to move out, to separate from the family home. Following resolution of this problem, the husband continued to be involved. Interestingly, the feelings of dissatisfaction transferred from his wife to him. When it came to my leaving, Mrs Mc was happily engaged at the local day hospital and it was $\mathrm{Mr}$ Mc who expressed the most anxiety at my departure which was only partly helped by my referring the couple to be seen at regular intervals by another doctor.

The above presents the dilemma of how far one should delve into wider family pathology in an out-patient setting. Once expectations began to change (they had never been seen as a family before) so more psychopathology was brought forward and the problem became more difficult to contain.

In considering doctor/patient relationships, it became important to develop insight into my own feelings and attitudes and not only how these might affect the patient but also what they can tell me about the patient.

Case 4: Mr J, a young man in his late $20 \mathrm{~s}$, was referred for a second opinion. The GP had written stating that he was asking to see a different psychiatrist. My reaction, prior to seeing him, was one of anger, as I did not feel qualified to give second opinions. Towards the end of my appointment with him, he began to ask my reasons for going into psychiatry. Unfortunately, I did not pick up why he was asking these questions. Then, just before he left, he said. "I hope you realise just how responsible your job is and how important it is to take it seriously. You have to deal with people's suffering; it's not something that can be taken lightly."
On reflection, it seems that on a more obvious level, $\mathrm{Mr} \mathrm{J}$ had picked up my negative feelings about seeing him. It is also possible to see that some of my feelings could have been ones passed on by others. He was referred to me inappropriately for a second opinion, after a short letter from a GP, who pointed out that it was Mr J's, rather than his, request.

The reaction of the therapist may be the first clue as to what is going on in the patient. The nature of the process by which $\mathrm{Mr} \mathbf{J}$ ended up in my clinic could reflect the feelings of others wanting to "dismiss" him by passing him on. It is unlikely to be coincidence that I also referred him on at the end of my interview with him.

A useful way of looking at this type of countertransference is, as Sandler (1976) pointed out, a "compromise formation between his (the analyst's) own tendencies and his reflexive acceptance of the role which the patient is forcing on him". I can only speculate as to what might have been different in the consultation had I been more aware and questioning of my own reactions.

\section{Comment}

"The doctor who is preoccupied with theories may fail to notice, recall or utilize for therapy quite ordinary but significant events in the consultation. He may instead pursue questions which are really side-issues of the patient's present problem, but which seem to fit in better with the doctor's own constructs." (Balint \& Norell, 1973)

Developing an approach to helping the sick person, rather than simply diagnosing illness, was the task Balint, a group of GPs and others set themselves in the early 1950s (Balint, 1957). By the early '70s, they developed an approach to patient care which involved understanding and utilising the doctor/ patient relationship (Balint \& Norell, 1973). Traditional diagnosis continued to be used but a global diagnosis system was also developed that took into account emotional and relationship life. They felt that traditional diagnosis is often not the best or, even a true, account of many problems encountered in general practice; further, it also carries the risk that patient and doctor may use it as a defence against discovering the emotional conflicts that may underlie the illness.

The feeling of being uncomfortable or finding it difficult to categorise patients diagnostically was a problem to me in the psychiatric out-patient clinic. This will be partly due to my inexperience but, when reading a paper by a medical student outlining his difficulties when starting clinical medicine (Goldin, 1990), I was reminded of my difficulties with working with the medical model. He described the relationship between himself and an anorexic patient on a medical ward and comments, "students face 
numerous demands in their relationships with their patients for which they are poorly prepared" and "medical education consists largely of learning facts and being taught to act, with little time for students to pause and reflect".

From a psychiatric trainee's point of view, with examinations, research and other academic pursuits in mind, it is often difficult to see beyond the immediate necessity of developing diagnostic and other skills fitting the traditional medical model that makes up the mainstream of psychiatry. My worry is that this leaves trainees with little chance of developing an understanding of relationships which is surely necessary for every psychiatrist. The difficulty of the task is highlighted in the out-patient setting where there is little time and consequently a pressure towards the information gathering-diagnosis-action system.

Yet the out-patient setting is rich in phenomena that become more understandable by broadening one's approach to include psychodynamic ideas. Encouraging trainees to take the opportunity of exploring psychodynamic approaches to the doctor/ patient relationship would, I believe, foster a deeper understanding and more flexible attitude. Time with

patients need not be an inhibiting factor (as the book Six Minutes for the Patient [Balint \& Norell, 1973] demonstrates). Prevailing ideology and one's own training requirements are.

\section{Acknowledgements}

Thanks to Drs K. Healey, N. Minto and S. Craske for their support, advice and encouragement.

\section{References}

Balint, M. (1957) The Doctor, His Patient and The Illness. London: Pitman Medical.

— \& Norell, J. S. (eds.) (1973) Six Minutes for the Patient: interaction in general practice consultation. London: Tavistock.

GoldiN, J. (1990) An account of a student/patient relationship during medical training. Journal of the Balint Society, 18, 19-21.

SANDLER, J. (1976) Countertransference and role responsiveness. International Review of Psychoanalysis, 3, 43-47.

Straus, A., Schatzman, L., Bucher, R. et al (1964) Psychiatric Ideologies and Institutions. New Brunswick and London: Transaction Books.

\title{
Innovations
}

\section{Working with psychiatric problems in probation}

\author{
Keith J. B. RIx, Consultant Psychiatrist, St James's University Hospital, Beckett Street, \\ Leeds LS9 7TF
}

Recent public concern about prisoners with psychiatric disorder, the deliberations of the Department of Health and Home Office Review of Health and Social Services for Mentally Disordered Offenders (the Reed Review) and the allocation by HM Govern- ment of funds for magistrates' courts to pay for duty psychiatrist schemes like the experimental scheme at Clerkenwell Magistrates' Court (James \& Hamilton, 1991) are raising the profile of the mentally disordered offender and focusing attention on a 